\title{
Air Pollution and Central Nervous System Disease: A Review of the Impact of Fine Particulate Matter on Neurological Disorders
}

\author{
Hyunyoung Kim ${ }^{1}$, Won-Ho Kim ${ }^{2}$, Young-Youl Kim ${ }^{1}$ and Hyun-Young Park ${ }^{3 *}$ \\ ${ }^{1}$ Division of Allergy and Respiratory Disease Research, Department of Chronic Disease Convergence Research, Korea \\ National Institute of Health, Cheongju-si, South Korea, ${ }^{2}$ Division of Cardiovascular Disease Research, Department of Chronic \\ Disease Convergence Research, Korea National Institute of Health, Cheongju-si, South Korea, ${ }^{3}$ Department of Precision \\ Medicine, Korea National Institute of Health, Cheongju-si, South Korea
}

OPEN ACCESS

Edited by:

Peter S. Hooda,

Kingston University, United Kingdom

Reviewed by:

Luke Michael Healy, McGill University, Canada Theodora Katsila,

National Hellenic Research

Foundation, Greece

*Correspondence:

Hyun-Young Park

hypark65@korea.kr

Specialty section: This article was submitted to

Exposome

a section of the journal

Frontiers in Public Health

Received: 25 June 2020 Accepted: 20 November 2020 Published: 16 December 2020

Citation:

Kim H, Kim W-H, Kim Y-Y and Park H-Y (2020) Air Pollution and Central Nervous System Disease: A

Review of the Impact of Fine Particulate Matter on Neurological

Disorders.

Front. Public Health 8:575330. doi: 10.3389/fpubh.2020.575330
Background: It is widely known that the harmful effects of fine dust can cause various diseases. Research on the correlation between fine dust and health has been mainly focused on lung and cardiovascular diseases. By contrast, the effects of air pollution on the central nervous system (CNS) are not broadly recognized.

Findings: Air pollution can cause diverse neurological disorders as the result of inflammation of the nervous system, oxidative stress, activation of microglial cells, protein condensation, and cerebral vascular-barrier disorders, but uncertainty remains concerning the biological mechanisms by which air pollution produces neurological disease. Neuronal cell damage caused by fine dust, especially in fetuses and infants, can cause permanent brain damage or lead to neurological disease in adulthood.

Conclusion: It is necessary to study the air pollution-CNS disease connection with particular care and commitment. Moreover, the epidemiological and experimental study of the association between exposure to air pollution and CNS damage is critical to public health and quality of life. Here, we summarize the correlations between fine dust exposure and neurological disorders reported so far and make suggestions on the direction future research should take.

Keywords: fine particulate matter, neurological disease, intervention, oxidative stress, epidemiological study

\section{INTRODUCTION}

Air pollution is known to be the most dangerous and important environmental risk factor in the world. According to a recent report by the World Health Organization (WHO), 4.2 and 3.8 million people die early each year due to external and indoor air pollution, respectively (1).

Due to its small size, fine particulate matter (PM) lingers in the atmosphere and can easily penetrate the lungs during respiration and disseminate through the body via blood vessels, causing adverse health effects. In particular, if exposed to fine dust over a long period of time, the immune system will deteriorate rapidly, increasing the risk of various diseases such as those of the cardiovascular system and skin as well as respiratory diseases such as colds, asthma, and bronchitis.

The International Agency for Research on Cancer (IARC) has designated fine dust as a first-grade carcinogen because of its high content of heavy metals and because pollution from automobile-induced smog particles and sulfur oxides is sufficient to cause cancer. 
A complex mixture of PM, gases, organic compounds, and inorganic compounds, air pollution is present both outdoors and indoors. PM is classified by aerodynamic diameter $(>2.5$ to $<10 \mu \mathrm{m}$, coarse particles, PM10; $<2.5 \mu \mathrm{m}$, fine particles, PM2.5; and $<100 \mathrm{~nm}$, ultrafine particulate matter, UFPM) andgiven the capability of fine and UFPM to reach the brain (2) -is of special concern to brain health. In particular, the major constituents of fine dust, such as polycyclic aromatic hydrocarbons (PAH), $\mathrm{NO}_{2}$, and $\mathrm{SO}_{2}$, are reportedly major causes of cardiovascular, respiratory, neurological, eye, and skin diseases.

Evidence of air pollution's hazardous effects on the central nervous system (CNS) has been accumulating recently. Ambient air pollution is now suspected of being a neurotoxicant, and mounting evidence from human epidemiological and animal studies suggests that air pollution may negatively affect the CNS and contribute to CNS disease (2). Furthermore, unlike other organs, the lung and brain are susceptible to the direct absorption of fine PM through the nasal olfactory mucosa $(3,4)$.

In addition, air pollution, especially PM2.5 and nitrogen oxides $\left(\mathrm{NO}_{\mathrm{x}}\right)$, is known to affect the CNS, causing systemic inflammation, neuroinflammation, and oxidative stress (5-7). A growing body of literature links exposure to various air pollutants with poor brain health and an increased incidence of neurological and psychiatric disorders such as cognitive decline, dementia, anxiety, depression, schizophrenia, and attention deficit hyperactivity disorder (ADHD). Here, we summarize the available published evidence regarding associations between neurological disease and air pollution across the lifespan. We also summarize the results of epidemiological and mechanistic studies on brain diseases and suggest remedial methods and future research directions aimed at minimizing the adverse health effects of fine dust.

\section{ASSOCIATION WITH NEUROLOGICAL DISORDERS}

\section{Dementia and Cognitive Function}

Exposure to contaminated external air is considered an environmental risk factor that promotes brain aging. Recently, several epidemiological studies have reported that the risk of developing dementia and Alzheimer's disease is increased by exposure to fine $\mathrm{PM}(\mathrm{PM}<2.5 \mu \mathrm{m})$ (8). Despite the recent growing evidence of neurological effects of air pollution on Alzheimer's disease and associated cognitive function, no definitive conclusions on causality can be drawn, because research is as yet insufficient and uncertainty about the underlying mechanisms persists.

The role of long-term exposure to air pollution in the onset of dementia is still controversial. However, in both epidemiological and toxicological studies, exposure to air pollution seems to be associated with a decrease in cognitive function (9-12).

A steady stream of reports has linked Alzheimer's disease and exposure to ambient-air particles. For example, in ApoE-/mutant mice exposed to fine dust, numbers of dopamine cells decreased by $29 \%$ compared with those of control groups breathing fresh air, indicating that fine dust has a significant impact on nerve cells (13). Moreover, continual exposure to PM2.5 neurotoxicity contributed to early decline of immediate free recall/new learning abilities, corresponding to the preclinical stage. This change was mediated by progressive atrophy of gray matter, which indicated an increased risk of Alzheimer's disease independent of cerebrovascular damage (14). Furthermore, a study in Rome found a positive association between residential exposure to $\mathrm{NO}_{\mathrm{x}}$ and ozone and first hospitalizations for dementia. Moreover, exposure to $\mathrm{PM}$ and $\mathrm{NO}_{\mathrm{x}}$ has been associated with hospitalizations for vascular dementia $(8,15,16)$.

Various biological pathways, such as systemic inflammation, oxidative stress, have been highlighted in attempts to explain the relationship between air pollution and brain dysfunction. It has been reported that air pollution causes metabolic abnormalities and oxidative stress in the brain. Specifically, air-pollutioninduced dysfunction of the insulin signaling system reportedly reduces cognitive function and increase the risk of dementia. In particular, the neural hyper-insulinemia, glucose resistance, and amyloid beta accumulation $(\mathrm{A} \beta$ ) was observed in genetically modified knock-out mice lacking the insulin-degrading enzyme (IDE) (17). Glucose resistance reportedly causes memory loss and hippocampal cell atrophy, and insulin resistance reduces glucose absorption in the cerebrum, thus increasing the risk of dementia $(18,19)$ (Figure 1). Furthermore, previous research suggests that fine dust (PM2.5) can trigger cognitive impairment and neurodegeneration through changes in the mitochondrial structure and function; specifically, PM2.5 inhalation was found to interfere with aerobic tricarboxylic acid metabolism and oxidative phosphorylation, subsequently reducing ATP production and consequently leading to hypophosphorylation of tau in the cortex of middle-aged mice. In addition, the production of excessive reactive oxygen species was implicated in this damage. These changes resulted in partial recovery after PM2.5 exposure was terminated (20).

\section{Stroke}

It is well-known that cardiovascular risk factors play an important role in the elevation of stroke incidence observed in highly polluted urban areas. The scientific data indicate that short-term exposure to air pollution is associated with an increased risk of stroke and acute coronary syndromes such as myocardial infarction. Out-of-hospital deaths from cardiac arrest are positively associated with ambient air pollution levels $(21,22)$. In addition, it has frequently been reported that the toxic substances found in fine dust contribute to thrombosis in blood vessels, which increases the rate of strokes $(23,24)$.

The association of stroke with air pollution is more researched than that with any other neurological disorder. According to reports so far, exposure to air pollution is also correlated with subclinical diseases underlying stroke. These include systemic inflammation, oxidative stress, atherosclerosis, thrombosis, and arrhythmia (23).

Several studies have implicated continuous exposure to PM2.5 in the causation of stroke (25-27). A recent study reported that $\mathrm{NO}_{2}$, the major component of air pollution, is one of the main causes of stroke. Moreover, short-term exposure to 


\title{
PM2.5
}

\author{
Neuro-inflammation (iNOS, TNF- $\alpha$, IL-1, \\ $\mathrm{NF} \kappa \beta)$ \\ $\downarrow$
}

A $\beta 42$ Accumulation

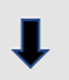

$\mathrm{A} \beta, \alpha$-Synuclein Aggregation $\longleftarrow \quad \mathrm{X} \beta$ degrading Enzyme (IDE)

$\downarrow$

Lipid Peroxidation and Astrogliosis (GFAP)

Atrophy of Hippocampal Cells

FIGURE 1 | Molecular mechanism of PM2.5 in dementia. Fine dust causes neuro-inflammation, which causes excessive accumulation of amyloid. Excessively accumulated amyloid usually should be decomposed by amyloid decomposition enzyme like IDE, but the malfunction of IDE causes neuronal cell death.

$\mathrm{SO}_{2}, \mathrm{NO}_{2}$, and PM10 was significantly associated with increased risk of ischemic stroke $(28,29)$. These toxic components are associated with elevation of the daily maximum heart rate, heart block frequency, and atrial fibrillation (30). Long-term residential exposure to locally emitted black carbon from traffic exhaust was associated with ischemic stroke incidence (31).

Many papers report on the correlation between air pollution and stroke mortality, but little is known about the specific subtypes of PM2.5 that are the most hazardous in this regard. Therefore, correlating types of pollutants with stroke incidence is very important for the assessment of health impacts (32) (Figure 2).

\section{Depression}

Depression is one of the most common mental health problems worldwide. According to a WHO report, more than 300 million people are living with depression, with an increase of $18 \%$ from 2005 to 2015 (33).

To date, many epidemiological papers have been published correlating air pollution with depression. However, this correlation remains controversial. The risk of depression is significantly increased with long-term exposure to PM2.5 and short-term exposure to $\mathrm{PM} 10, \mathrm{NO}_{2}, \mathrm{SO}_{2}$, and $\mathrm{CO}$, but not exposure to $\mathrm{O}_{3}$ (34-36). On the other hand, other reports suggest that $\mathrm{O}_{3}$ is strongly associated with depression in women $(37,38)$. In addition, short-term exposure to air pollution did not produce clear pathological alterations in mood in a healthy elderly population (39).
In a study of mice exposed to air pollution, expression of the gene underlying the oxidative stress response was attenuated when the mice were injected with an inhibitor of cortisol production. However, when they were injected with cortisol itself, the oxidative stress-causing gene was activated (40). These results suggest that cortisol level is a key player in the effect of air pollution on depression. The brain is highly sensitive to glucocorticoids, such as cortisol, which is a stress hormone with important roles in cognition and depression. The response to stress starts in the CNS and acts via the hypothalamus and pituitary gland to increase the secretion of cortisol from the adrenal cortex $(17,41)$. Recent epidemiological research revealed the correlation between air pollution and cortisol levels, and that $\mathrm{NO}_{2}, \mathrm{PM} 2.5$, and PM10 were reportedly associated with high wake-up cortisol $(42,43)$. When HPA is activated by air pollution and glucocorticoid binds to the glucocorticoid receptor (GR), the associated neurotrophic factor and the genes associated with inflammatory reactions, apoptosis, and metabolism are expressed, resulting in impaired neurogenesis, neurotoxicity, and glial cell reactivity. This eventually leads to cognitive decline, dementia, and depression $(17,40,44)$.

A clear demonstration of a causal relationship between air pollution (or some toxic component thereof) and depression remains elusive, and further research on this question is needed.

\section{Multiple Sclerosis}

Multiple sclerosis (MS) is a chronic disease of the central nervous system that is caused by inflammatory reactions or neurodegeneration. This prevalence of MS is $\sim 2.5$ million. While 


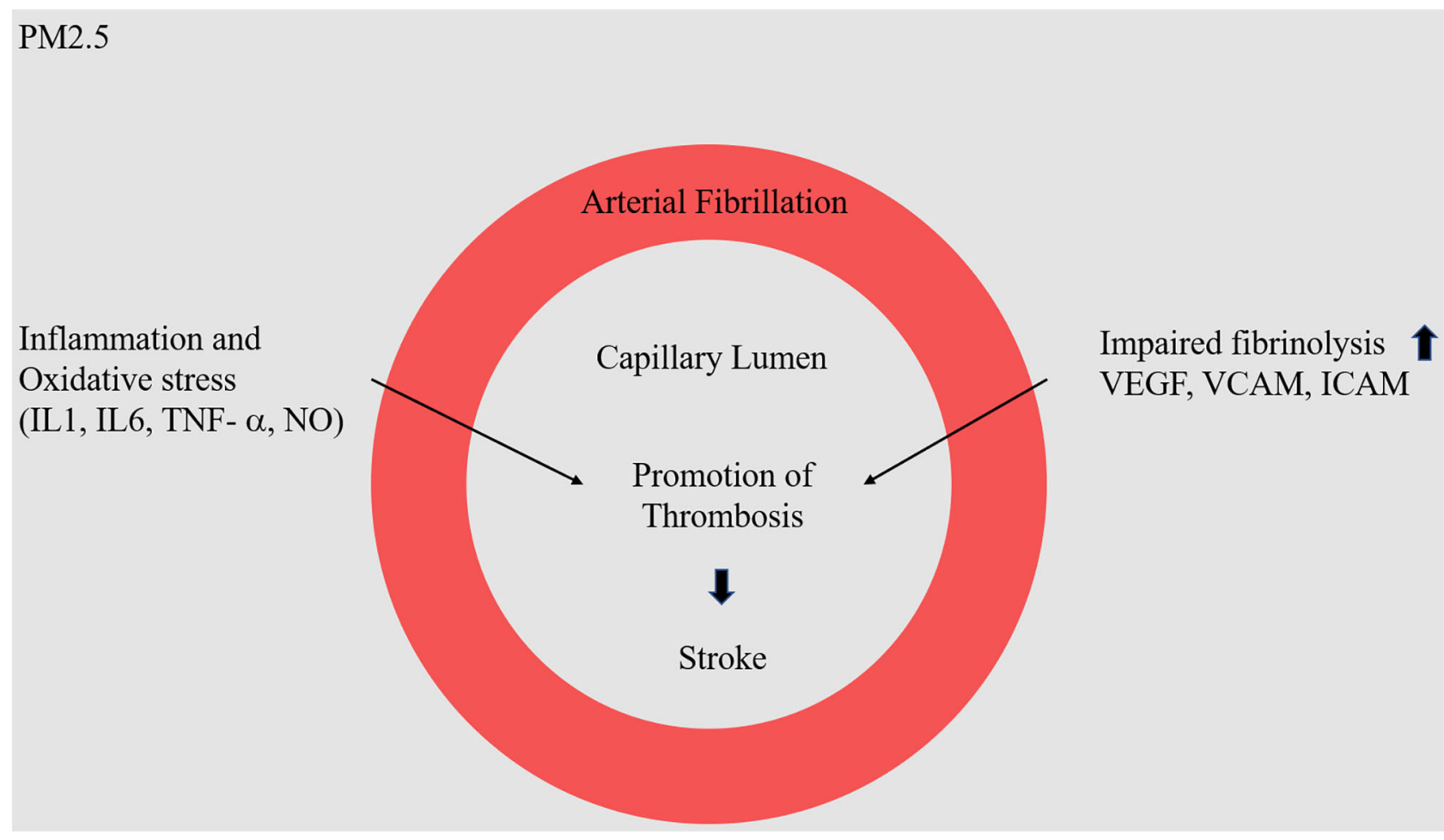

FIGURE 2 | Molecular mechanism of PM2.5 in stroke. Fine dust $\left(\mathrm{NO}^{-}, \mathrm{O}_{3}\right.$ ) enters the blood vessel, it will cause inflammatory and oxidative stress reactions. In particular, as the expression of VEGF, VCAM, and ICAM protein increases, there is a high probability of causing problems in the physical barrier in blood vessels, causing arterial fibrillation.

the underlying etiology of autoimmune diseases remains unclear, environmental and genetic factors have been implicated as major contributors. According to recent studies, about $40-70 \%$ of all autoimmune diseases can be explained by environmental factors, including air pollution, sunlight, ultraviolet rays, vitamin D, Epstein-Barr virus (EBV), smoking, and secondhand smoke (45-47).

Several studies have investigated the correlation between air pollution and MS, and although the results have been conflicting, they can be largely summarized in terms of three hypotheses. First, that particulate matter is absorbed into the lungs through the respiratory tract, inducing pulmonary/systemic inflammation and the activation of $\mathrm{T}$ cells, which then secrete proinflammatory cytokines in the brain; second, that particulate matter absorbed directly through the olfactory bulb may induce inflammatory reactions in the brain; and third, that epigenetic mutations caused by fine dust influence the onset of MS (48).

According to a recent analysis of the CSF in healthy children, the levels of IL-2, IL-6, and MIF (MIF) increased in children exposed to high concentrations of air pollution. IL-2 specifically has been established as a target of MS treatment (49). The reported induction of inflammation and oxidative stress in the brain by air pollution may affect brain autoimmunity, which may consequently influence MS disease or development (50).

While research on smoking and other environmental factors has considered their roles in DNA modification and the prevalence of MS, studies on fine dust have tended to focus more on the correlation between oxidative stress and inflammation or MS than on DNA modification $(50,51)$.

According to epidemiological studies, fine dust can be a risk factor for MS (52-54). The results of epidemiological surveys conducted in Italy showed that that air pollution may be an additional environmental risk factor that might contribute to the pathophysiology of MS (54).

In addition, a study that examined the changes in brain MRI findings of MS patients due to PM10 exposure confirmed that PM10 caused MS favoring inflammatory reactions (6). However, few studies have reported contrary findings. An examination of the long-term effects of air pollution revealed that that PM2.5, $\mathrm{NO}_{2}$, and $\mathrm{O}_{3}$ did not affect MS prevalence, and other cohort studies showed no correlation between air pollution and MS risk $(6,55)$. Since epidemiological findings about the correlation between fine dust and MS disease are still contextual, more epidemiological, and cohort studies are needed.

\section{Schizophrenia}

Schizophrenia is a chronic and severe mental disorder affecting more than 21 million people worldwide. It is generally accepted that mental illness is more prevalent among urban residents than rural $(56,57)$. A meta-analysis of the regional prevalence of mental illness found a $30 \%$ higher rate of mental illness among urban dwellers than their non-urban counterparts; the rate was $21 \%$ higher for anxiety disorders and 39\% higher for mood disorders (58). Furthermore, a time series study of a 


\section{PM2.5 \\ Cerebral cortex \\ $\operatorname{COX} 2 \uparrow, \operatorname{Arg} 1 \uparrow$ \\ $\longrightarrow$ Glial cell activation \\ Microglia (Iba1^) \\ Astrocyte (GFAP \\ Neuro-inflammation \\ Oxidative stress \\ Cytokine IL-1a, IL-2, IL-4, IL-6, IL-10, IFN- $\gamma$, GM-CSF, TNF- $\alpha$ \\ Synapse \\ Presynaptic protein : Synaptophysin \\ Working memory deficit \\ Postsynaptic protein : PSD 95 (Unchanged) \\ Spleen \\ Cytokine IL-2, I-L6, IL-10, TNF- $\alpha$ \\ Long-term inhibitory effect \\ FIGURE 3 | Molecular mechanism of PM2.5 in Neurodevelopment. In case of exposure to fine dust in fetal conditions, oxidative stress and inflammatory reactions occur in the cerebral cortex. Also, abnormal protein expression in synapses can affect working memory. Exposure to fine dust in fetal conditions also affects other organs, which can lead to long-term memory deficiencies.}

possible link between outpatient visits because of schizophrenia and exposure to short-term air pollution reported that shortterm exposure to air pollution ( $\mathrm{PM} 10, \mathrm{SO}_{2}$, and $\left.\mathrm{NO}_{2}\right)$ was associated with an increased risk of daily outpatient visits because of schizophrenia (59).

Several studies have been published in recent years on the correlation between the prevalence of mental illness and levels of fine airborne $\operatorname{PM}(7,60,61)$. According to a recent study, teenagers exposed to four types of air pollutant $-\mathrm{NO}_{2}, \mathrm{NO}_{\mathrm{x}}$, PM2.5, and PM10-have a 60\% higher rate of mental illness than do those not so exposed $(60,62)$. In addition, a Chinese study that examined the number of outpatient visits by patients with schizophrenia and its correlation with air pollution $\left(\mathrm{PM}_{10}, \mathrm{SO}_{2}\right.$, and $\mathrm{NO}_{2}$ ) found that outpatient visits increased significantly if patients were exposed to outside air pollution for only a short time $(59,63)$. Moreover, the severity of schizophrenia symptoms was exacerbated by high ambient PM2.5 concentrations in patients over 65 years of age (64). These findings show that, if continuously exposed to fine dust, all age groups are affected by an exacerbation and increased prevalence of schizophrenia. However, despite many epidemiological reports showing a link between fine dust and schizophrenia, few reports address the question of how fine dust might affect the development of schizophrenia mechanistically.

\section{ADHD}

Many studies over the past decade report that air pollution has a negative impact on child brain development, especially on the triggers of ADHD and autism spectrum disorder (ASD) (65). Several genetic and environmental factors are suspected of affecting the ASD phenotype, including air pollution, exposure to pesticides, maternal infections, inflammatory conditions, dietary factors, and administration of antibiotics during pregnancy.
The association of fine dust with ADHD was investigated by a Danish cohort study that ran from 1992 to 2007. The results showed that the higher the concentration of $\mathrm{PM} 2.5$ and $\mathrm{NO}_{2}$ in residential areas, the higher the incidence of $\mathrm{ADHD} ; \mathrm{NO}_{2}$ had a particularly clear association (66). Recent reports suggest that exposure to PM late in pregnancy significantly decreases the area of the corpus callosum (CC) of the brain, and a reduction of the CC area of $50 \mathrm{~mm}^{3}$ leads to significantly higher hyperactivity sub-scores (67).

Few studies have investigated a direct correlation between fine dust and ADHD onset. Although some epidemiological data may be correlated, further research on the exact mechanism is needed.

\section{Neurodevelopment}

It is known that several chemicals concealed in the living environment act as major toxins in neural development. In particular, airborne fine PM contains toxic substances such as lead, methylmercury, arsenic, polychlorinated biphenyls, and toluene, and these have neurotoxic activity and are thought to affect nerve development (68).

Continuous exposure to high levels of ambient air pollution during pregnancy can lead to a greater negative effect on brain development than exposure during childhood. Because the structure of the brain is established during fetal life, exposure to substances originating in air pollution in utero can lead to permanent brain damage or to cognitive impairment in old age (69). A cohort study reported that exposure to PM2.5 and $\mathrm{O}_{3}$ at an early stage of development was associated with neurodevelopmental delay $(70,71)$ (Figure 3).

A recent study investigating the mechanistic link between fine dust and neurogenesis reported that human nerve cells treated with ultrafine dust showed significant increases in levels of the messenger RNA specifying metallothioneins $1 \mathrm{~A}$ 
TABLE 1 | Evidence of association between ambient air pollution and neurological disease.

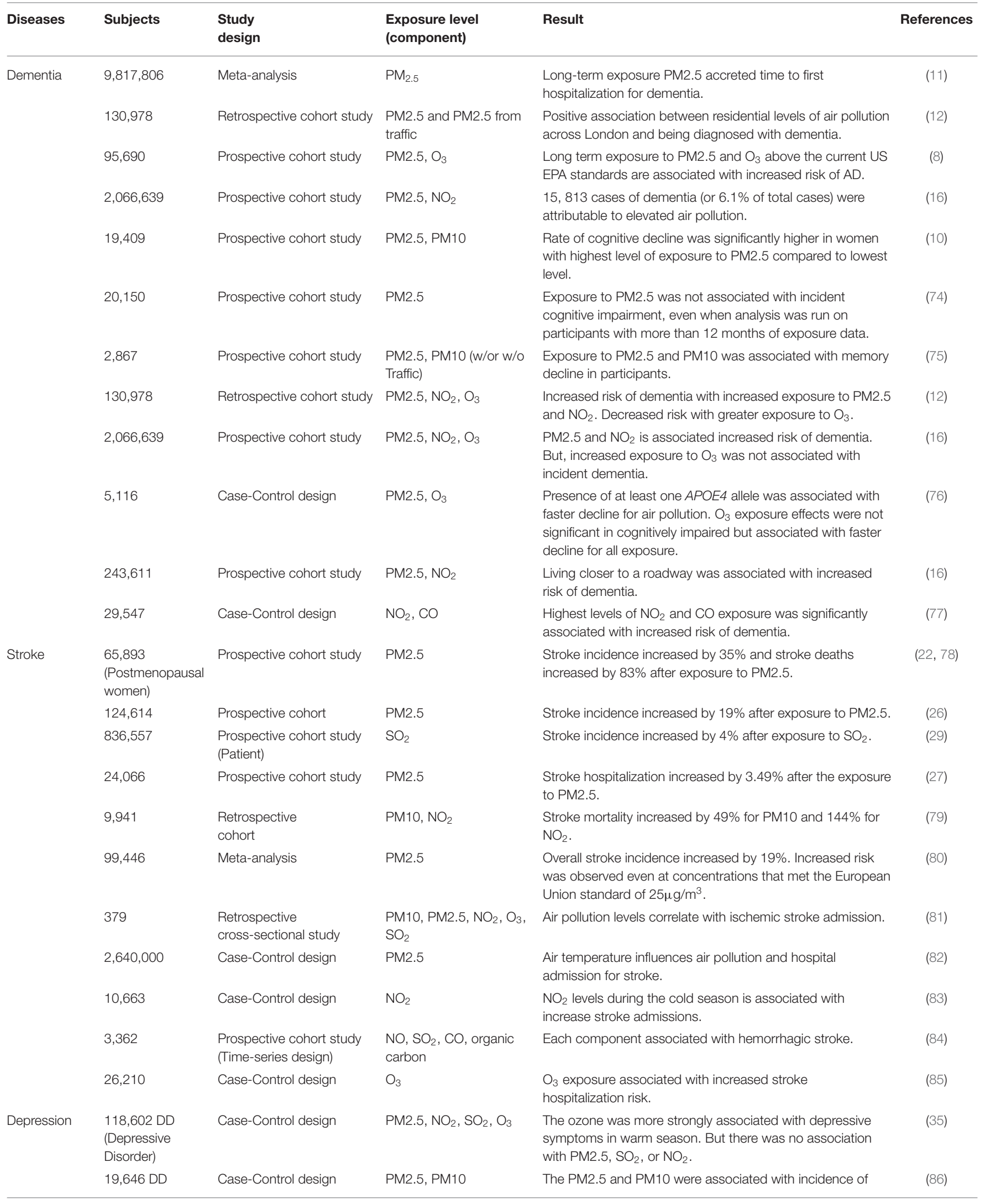


TABLE 1 | Continued

\begin{tabular}{|c|c|c|c|c|c|}
\hline Diseases & Subjects & $\begin{array}{l}\text { Study } \\
\text { design }\end{array}$ & $\begin{array}{l}\text { Exposure level } \\
\text { (component) }\end{array}$ & Result & References \\
\hline & & & & depression, and aging is a susceptibility factor. & \\
\hline & $27,047 \mathrm{DD}$ & Time-series study & $\mathrm{PM} 2.5, \mathrm{NO}_{2}, \mathrm{SO}_{2}, \mathrm{O}_{3}$ & $\begin{array}{l}\text { The PM2.5, } \mathrm{NO}_{2}, \mathrm{SO}_{2} \text {, and } \mathrm{CO} \text { had significant association } \\
\text { with depression in warm season. }\end{array}$ & $(38)$ \\
\hline & 4,985 DD & Case-Control design & $\mathrm{PM} 10, \mathrm{NO}_{2}, \mathrm{SO}_{2}, \mathrm{O}_{3}$ & $\begin{array}{l}\text { The PM10, } \mathrm{NO}_{2}, \mathrm{SO}_{2} \text {, and } \mathrm{CO} \text { had significant association } \\
\text { with depression. }\end{array}$ & (36) \\
\hline & $680 \mathrm{DD}$ & Case-Control design & $\mathrm{O}_{3}$ & The $\mathrm{O}_{3}$ was strongly associated with depression in women. & $(37)$ \\
\hline & 973 DD & Prospective cohort study & PM2.5 & $\begin{array}{l}\text { The PM2.5 is associated with incidence of depression and } \\
\text { chronic disease is a susceptibility factor. }\end{array}$ & $(87)$ \\
\hline \multirow[t]{7}{*}{ Schizophrenia } & 943,027 & Meta-analysis & Urban vs. suburban & $\begin{array}{l}\text { Natural environments during childhood may be important for } \\
\text { schizophrenia prevention. }\end{array}$ & $(57)$ \\
\hline & $\begin{array}{l}\text { 10,947 MDs } \\
\text { (Mental Disorder) }\end{array}$ & $\begin{array}{l}\text { Case-Control design } \\
\text { (Time-series) }\end{array}$ & PM2.5, PM10, PMc & $\begin{array}{l}\text { PM exposure might be an important trigger of } \\
\text { hospitalizations for MDs. }\end{array}$ & $(61)$ \\
\hline & $\begin{array}{l}\text { 1,193 SP } \\
\text { (Schizophrenia } \\
\text { patients) }\end{array}$ & Cross-sectional Study & PM2.5 & $\begin{array}{l}\text { Ambient PM2.5 concentration was associated with } \\
\text { exacerbation of schizophrenia. }\end{array}$ & $(64)$ \\
\hline & $34,865 \mathrm{SP}$ & $\begin{array}{l}\text { Case-Control design } \\
\text { (Time-series) }\end{array}$ & $\mathrm{PM} 2.5, \mathrm{SO}_{2}, \mathrm{NO}_{2}$ & $\begin{array}{l}\text { Ambient air pollution ( } \mathrm{PM} 10, \mathrm{SO}_{2}, \mathrm{NO}_{2} \text { ) can be associated } \\
\text { with increased risk of daily outpatient visits for schizophrenia. }\end{array}$ & (59) \\
\hline & $11,373 \mathrm{MDs}$ & $\begin{array}{l}\text { Case-Control design } \\
\text { (Time-series) }\end{array}$ & $\mathrm{NO}_{2}$ & $\begin{array}{l}\text { Short-term exposure to } \mathrm{NO}_{2} \text { may be associated with } \\
\text { increased schizophrenia hospital admissions. }\end{array}$ & (62) \\
\hline & $\begin{array}{l}2,232 \\
\text { (Children) }\end{array}$ & Cross-sectional study & NOx, PM2.5, PM10 & $\begin{array}{l}\text { Air pollution exposure-particularly } \mathrm{NO}_{2} \text { and } \mathrm{NO}_{x} \text {-was } \\
\text { associated with increased odds of adolescent psychotic } \\
\text { experiences, which partly explained the association between } \\
\text { urban residency and adolescent psychotic experiences. }\end{array}$ & (60) \\
\hline & 3,469 MDs & $\begin{array}{l}\text { Case-Control design } \\
\text { (Time-series) }\end{array}$ & $\mathrm{PM} 10, \mathrm{SO}_{2}, \mathrm{NO}_{2}$ & $\begin{array}{l}\text { It significantly increased the risk of schizophrenia episode in } \\
\text { subjects who were male, aged 20-59, farmers, and workers. }\end{array}$ & (63) \\
\hline
\end{tabular}

MD, Mental Disorder Patient; DD, Depressive Disorder Patient; SP, Schizophrenia Patient.

and $1 \mathrm{~F}$. The researchers also found that air pollution affected DNA methylation, which in turn affected protein expression at synapses. Another study found that exposure to fine dust in pregnancy not only lowers IQ, but also decreases levels of brain-derived neurotrophic factor, leading to lower graymatter volumes in the brain (14). Further research on the molecular mechanism of the link between fine dust exposure and neurodevelopment seems necessary $(72,73)$.

The evidence of an association between ambient air pollution and neurological disease in general is summarized in Table $\mathbf{1 .}$

\section{PATHOPHYSIOLOGICAL MECHANISMS IN THE NERVOUS SYSTEM}

Air-polluting substances could potentially reach the brain via the olfactory tract, the gastro-intestinal tract/vagus nerve, or the blood-brain barrier (BBB). The most direct of these routes is direct absorption into the brain through the olfactory bulb. Although the biological mechanisms by which fine dust affects brain diseases are unclear, it has been reported that oxidative stress and inflammatory reactions are the two major processes by which air pollution exerts its toxic systemic and CNS effects $(4,88,89)$.

In addition to the direct input of fine dust into the brain, there is an indirect absorption path into the brain through respiratory intake. In this case, the indirect input causes systematic inflammation and leads to circulating cytokines that pass through the BBB. Astrocytes in the brain respond to the neuroinflammation and oxidative stress by eventually inducing cell death (89).

In an animal study, oxidative stress was examined as a function of brain region by measuring lipid peroxidation after exposure to diesel-exhaust particulates (DEP). Elevations in a number of pro-inflammatory cytokines (IL-1 $\alpha$, IL-6, IL-10, IL13, IL-5, and TNF- $\alpha$ ) were observed, particularly in the olfactory bulb and hippocampus, but DEP caused an increase in lipid peroxidation in all brain regions, with levels of inflammatory cytokines increasing and levels of the pleiotropic cytokine IL-9 decreasing $(4,90,91)$.

According to a recent study, the neurotoxicity induced by DEP can be mediated by the inflammatory reaction of microglial cells. DEP is neurotoxic only to neurons co-cultured with microglial cells and not to neurons alone. Further, these effects are reversible when the microglial cells involved are treated with pioglitazone, an antagonist of the peroxisome proliferatoractivated receptor-gamma (PPAR- $\gamma$ ) (41). PPARs are known to be ligand-activated transcription factors, regulating genes essential for various metabolic processes and cell differentiation, but also exerting anti-inflammatory actions after brain injury or in neurodegenerative diseases (92).

Oxidative stress produced by DEP is also closely related to neurodegenerative disease. In a whole-body exposure study in mice, $\mathrm{A} \beta_{1-42}$ and tau protein, which are markers 


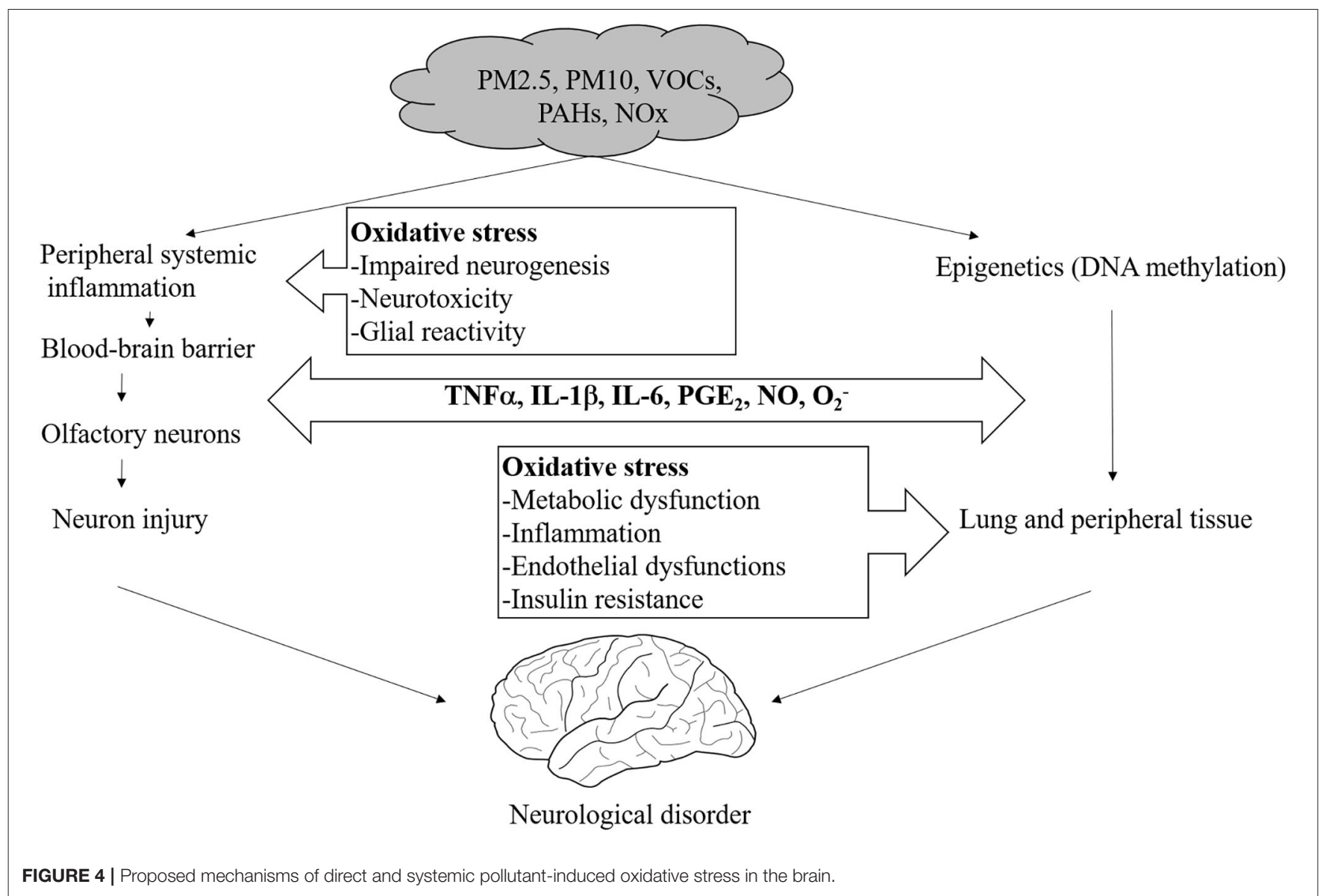

for Alzheimer's disease, showed increased levels in the frontal and temporal lobes. Moreover, $\alpha$-synuclein, the causative protein of Parkinson's disease, showed increased levels in the midbrain. These two brain regions are closely related to schizophrenia, depression, dementia, and Parkinson's disease (4).

In addition, recent studies have shown that air pollutants alter BBB function. For example, aluminum nanoparticles have been reported to injure endothelial cells and damage the BBB (93). Human exposure to air pollution results in endothelialcell damage in the cerebral vasculature, with increases in the expression of intercellular adhesion molecules (ICAMs) and vascular cell adhesion molecules (VCAMs) (94). A rat wholebrain in vitro study showed that exposure to PM causes the production of cytokines and reactive oxygen species, a decrease in the expression of various tight-junction proteins, and changes in the intracellular signaling pathway that governs the expression and function of the xenobiotic transporter (95) (Figure 4).

Various omics analyses were conducted to identify the physiological mechanisms of various diseases caused by fine dust. Genetic studies reported changes in DNA additives, telomere length, and mitochondria DNA (mtDNA) content caused by fine dust (PM2.5, PAH, $\mathrm{NO}_{2}$ ) (96-98). Transcriptomics analysis revealed a reduction in the expression of BDNF and CYP1A1 (99), and epigenetics analysis showed changes in DNA methylation [mtDNA, lone interspersed nuclear element
1(LINE-1), leptin (LEP) promotor] and miRNA expression (mir-21, miR-146a, and miR-22) (99-101). Proteomics analysis found an increase in $\mathrm{AHH}$ activity and decreases in pyruvate kinase, MT, and GST activity (102-104).

\section{Interventions to Reduce the Impact of Air Pollution on Neurodegenerative Disease}

To date, the most common intervention in neurological diseases caused by air pollution is to minimize exposure to ambient air contaminants.

Several recent reports suggest that dietary supplementation with antioxidants such as certain vitamins reduces the harmful effects of fine dust. In particular, it was reported that vitamins $\mathrm{C}$ and $\mathrm{E}$ prevent oxidative damage from exposure to $\mathrm{O}_{3}$ and PM2.5, and unsaturated fatty acids such as fish oil and olive oil have the effect of mitigating cardiovascular reactions to shortterm exposure to air pollutants (105). It was also reported that the effects on the cardiovascular system of exposure to fine dust are reduced by dietary B vitamins (106). Moreover, PM2.5 causes methylation of the genes related to energy metabolism in mitochondria, changes that are reduced by dietary B vitamins (107). However, these studies had small sample sizes and did not examine the chemical components of the fine particulates. Further research is needed on whether antioxidant foods can mitigate the general effects of fine dust. 
To mitigate diseases caused by environmental pollution, the complexities of environmental, dietary, and sociological parameters related to the interaction of genes and epigenetics will have to be considered in addition to segmental research; hence, future research requires high-level biological coupling.

Using the complex Exposome paradigm, the European Research Group recently proved that contaminated industrial sites are directly linked to health problems. This study is thought to be an important example of future research methodology for investigations into diseases attributable because of environmental pollution $(108,109)$.

Fine dust has varied effects on neurological diseases because its composition varies from source to source. Therefore, no one intervention method can be appropriate in all circumstances. At present, minimizing exposure remains the only way to minimize damage. General medical policy is as follows: Prevent finedust damage to the bedridden patient with neurological disease, respiratory disease, etc. by managing blood pressure, diabetes, and obesity, and by counseling the patient to refrain from outdoor activities and strenuous exercise. Wearing masks is also recommended in cases of severe exposure to fine dust, and if the disease worsens, the patient is advised to visit a hospital.

To date, research on the health effects of fine PM has accounted for most short-term exposure studies; several papers have described fine-dust effects on acute respiratory diseases. However, interventional studies are challenging because most neurological diseases aggravated by fine PM would involve longterm exposure.

Therefore, to mitigate health damage caused by fine dust, personal efforts such as improvement in indoor air quality should be encouraged, and public health efforts should be made to reduce fine dust in the air generally. Until now, most of the papers on general intervention studies are written from a preventive medical and epidemiological point of view, but few studies have investigated mitigation based on biological mechanisms. Due to the seriousness of the fine-dust problem that has become known in recent years, we hope that many interventional studies based on biological mechanisms will be conducted in the near future.

\section{FUTURE DIRECTIONS}

As many studies have shown, air pollution has a deleterious effect on neurological disorders. However, to prove this relationship clearly and find a way to mitigate the effects of air pollution, further systematic studies with improved precision seem necessary.

The rates of diseases such as dementia and depression continue to rise year by year in Korea, where fine dust levels are above average compared with other Organization for Economic Cooperation and Development countries. Of course, many factors are involved beyond the effects of air pollution. However,

\section{REFERENCES}

1. Nabizadeh R, Yousefian F, Moghadam VK, Hadei M. Characteristics of cohort studies of long-term exposure to PM2.5: a systematic review. multiple studies have found an epidemiological link between air pollution and certain neurological diseases. Therefore, a major interventional study will be required in the future to investigate a possible causal relationship.

\section{LIMITATIONS AND CONCLUSION}

This review has certain important limitations. First, this is not a systematic review, and therefore there were no specific criteria for selecting the included articles, and results were not analyzed using statistical methods. In addition, the scope of our review of air pollution and cerebral neuropathy was wide, and individual diseases have not been discussed in-depth. Finally, previously known harmful mechanisms, such as oxidative stress and inflammation, and new or disease-specific mechanisms have not been covered in detail. Additional work will be required to determine the precise impact of air pollution on each neurological disorder.

It is time to go beyond epidemiological studies and first verify, then elucidate, the effects of fine dust on various diseases through research into biological mechanisms. Most of the mechanistic studies so far have focused on two basic diseasecausing processes: oxidative stress and inflammation. Research on any mechanisms specific to fine dust will also be necessary. In addition, there is a need for evidence-based treatment approaches to the problem of exacerbation of underlying disease by fine dust.

Epidemiological studies are also required to analyze the causal relationship of fine dust to neurological diseases with respect to composition and source. In addition, researchers should seek ways to minimize the impact of fine dust on brain diseases through biological mechanistic studies.

\section{AUTHOR CONTRIBUTIONS}

HK was a major contributor in writing the manuscript. W-HK participated in the data and interpretation of the part of the Stroke. Y-YK participated in the collection and interpretation of epidemiological data. H-YP was a contributor in the composition and writing of the whole idea and thesis. All authors made contributions to the interpretation of data and revising the manuscript. All authors read and approved the final manuscript.

\section{FUNDING}

This study was supported by the Korean Research Centers for Disease Control and Prevention [grant nos. 4845-300-304 and 2019-NI-102-00].

\section{ACKNOWLEDGMENTS}

We thank Drs. Jae-kyung Sung and Geom-Kyu Lee for assistance.
Environ Sci Pollut Res Int. (2019) 26:30755-71. doi: 10.1007/s11356-019-0 6382-6

2. Calderon-Garciduenas L, Calderon-Garciduenas A, Torres-Jardon R, AvilaRamirez J, Kulesza RJ, Angiulli AD. Air pollution and your brain: what do 
you need to know right now. Prim Health Care Res Dev. (2015) 16:32945. doi: 10.1017/S146342361400036X

3. Ajmani GS, Suh HH, Pinto JM. Effects of ambient air pollution exposure on olfaction: a review. Environ Health Perspect. (2016) 124:168393. doi: 10.1289/EHP136

4. Costa LG, Cole TB, Coburn J, Chang YC, Dao K, Roque PJ. Neurotoxicity of traffic-related air pollution. Neurotoxicology. (2017) 59:133-9. doi: 10.1016/j.neuro.2015.11.008

5. Andersen ZJ, Pedersen M, Weinmayr G, Stafoggia M, Galassi C, Jorgensen JT, et al. Long-term exposure to ambient air pollution and incidence of brain tumor: the European Study of Cohorts for Air Pollution Effects (ESCAPE). Neuro Oncol. (2018) 20:420-32. doi: 10.1093/neuonc/nox163

6. Bergamaschi R, Cortese A, Pichiecchio A, Berzolari FG, Borrelli P, Mallucci G, et al. Air pollution is associated to the multiple sclerosis inflammatory activity as measured by brain MRI. Mult Scler. (2018) 24:157884. doi: $10.1177 / 1352458517726866$

7. Braithwaite I, Zhang S, Kirkbride JB, Osborn DPJ, Hayes JF. Air pollution (particulate matter) exposure and associations with depression, anxiety, bipolar, psychosis and suicide risk: a systematic review and meta-analysis. Environ Health Perspect. (2019) 127:126002. doi: 10.1289/EHP4595

8. Jung CR, Lin YT, Hwang BF. Ozone, particulate matter, and newly diagnosed Alzheimer's disease: a population-based cohort study in Taiwan. J Alzheimers Dis. (2015) 44:573-84. doi: 10.3233/JAD-140855

9. Power MC, Weisskopf MG, Alexeeff SE, Coull BA, Spiro A 3rd, Schwartz J. Traffic-related air pollution and cognitive function in a cohort of older men. Environ Health Perspect. (2011) 119:682-7. doi: 10.1289/ehp.1002767

10. Weuve J, Puett RC, Schwartz J, Yanosky JD, Laden F, Grodstein F. Exposure to particulate air pollution and cognitive decline in older women. Arch Intern Med. (2012) 172:219-27. doi: 10.1001/archinternmed.2011.683

11. Kioumourtzoglou MA, Schwartz JD, Weisskopf MG, Melly SJ, Wang Y, Dominici F, et al. Long-term PM2.5 exposure and neurological hospital admissions in the northeastern United States. Environ Health Perspect. (2016) 124:23-9. doi: 10.1289/ehp.1408973

12. Carey IM, Anderson HR, Atkinson RW, Beevers SD, Cook DG, Strachan DP, et al. Are noise and air pollution related to the incidence of dementia? A cohort study in London, England. BMJ Open. (2018) 8:e022404. doi: 10.1136/bmjopen-2018-022404

13. Veronesi B, Makwana O, Pooler M, Chen LC. Effects of subchronic exposures to concentrated ambient particles. VII. Degeneration of dopaminergic neurons in Apo E-/- mice. Inhal Toxicol. (2005) 17:23541. doi: 10.1080/08958370590912888

14. Sram RJ, Veleminsky M Jr, Veleminsky M Sr, Stejskalova J. The impact of air pollution to central nervous system in children and adults. Neuro Endocrinol Lett. (2017) 38:389-96.

15. Cerza F, Renzi M, Gariazzo C, Davoli M, Michelozzi P, Forastiere $\mathrm{F}$, et al. Long-term exposure to air pollution and hospitalization for dementia in the Rome longitudinal study. Environ Health. (2019) 18:72. doi: 10.1186/s12940-019-0511-5

16. Chen H, Kwong JC, Copes R, Hystad P, van Donkelaar A, Tu $\mathrm{K}$, et al. Exposure to ambient air pollution and the incidence of dementia: a population-based cohort study. Environ Int. (2017) 108:2717. doi: 10.1016/j.envint.2017.08.020

17. Thomson EM. Air pollution, stress, and allostatic load: linking systemic and central nervous system impacts. J Alzheimers Dis. (2019) 69:597614. doi: 10.3233/JAD-190015

18. Willette AA, Bendlin BB, Starks EJ, Birdsill AC, Johnson SC, Christian BT, et al. Association of insulin resistance with cerebral glucose uptake in late middle-aged adults at risk for Alzheimer disease. JAMA Neurol. (2015) 72:1013-20. doi: 10.1001/jamaneurol.2015.0613

19. Block ML, Calderon-Garciduenas L. Air pollution: mechanisms of neuroinflammation and CNS disease. Trends Neurosci. (2009) 32:50616. doi: 10.1016/j.tins.2009.05.009

20. Gao R, Ku T, Ji X, Zhang Y, Li G, Sang N. Abnormal energy metabolism and tau phosphorylation in the brains of middle-aged mice in response to atmospheric PM2.5 exposure. J Environ Sci (China). (2017) 62:14553. doi: 10.1016/j.jes.2017.06.037

21. Cascio WE. Proposed pathophysiologic framework to explain some excess cardiovascular death associated with ambient air particle pollution: insights for public health translation. Biochim Biophys Acta. (2016) 1860:286979. doi: 10.1016/j.bbagen.2016.07.016

22. Miller KA, Siscovick DS, Sheppard L, Shepherd K, Sullivan JH, Anderson GL, et al. Long-term exposure to air pollution and incidence of cardiovascular events in women. N Engl J Med. (2007) 356:44758. doi: 10.1056/NEJMoa054409

23. Hamanaka RB, Mutlu GM. Particulate matter air pollution: effects on the cardiovascular system. Front Endocrinol (Lausanne). (2018) 9:680. doi: 10.3389/fendo.2018.00680

24. Meng Q, Richmond-Bryant J, Lu SE, Buckley B, Welsh WJ, Whitsel EA, et al. Cardiovascular outcomes and the physical and chemical properties of metal ions found in particulate matter air pollution: a QICAR study. Environ Health Perspect. (2013) 121:558-64. doi: 10.1289/ehp.1205793

25. Scheers H, Jacobs L, Casas L, Nemery B, Nawrot TS. Long-term exposure to particulate matter air pollution is a risk factor for stroke: meta-analytical evidence. Stroke. (2015) 46:3058-66. doi: 10.1161/STROKEAHA.115.009913

26. Lipsett MJ, Ostro BD, Reynolds P, Goldberg D, Hertz A, Jerrett M, et al. Long-term exposure to air pollution and cardiorespiratory disease in the California teachers study cohort. Am J Respir Crit Care Med. (2011) 184:82835. doi: 10.1164/rccm.201012-2082OC

27. Kloog I, Coull BA, Zanobetti A, Koutrakis P, Schwartz JD. Acute and chronic effects of particles on hospital admissions in New-England. PLoS One. (2012) 7:e34664. doi: 10.1371/journal.pone.0034664

28. Wang Z, Peng J, Liu P, Duan Y, Huang S, Wen Y, et al. Association between short-term exposure to air pollution and ischemic stroke onset: a time-stratified case-crossover analysis using a distributed lag nonlinear model in Shenzhen, China. Environ Health. (2020) 19:1. doi: 10.1186/s12940-019-0557-4

29. Atkinson RW, Carey IM, Kent AJ, van Staa TP, Anderson HR, Cook DG. Long-term exposure to outdoor air pollution and incidence of cardiovascular diseases. Epidemiology. (2013) 24:44-53. doi: 10.1097/EDE.0b013e318276ccb8

30. Babadjouni RM, Hodis DM, Radwanski R, Durazo R, Patel A, Liu Q, et al. Clinical effects of air pollution on the central nervous system; a review. J Clin Neurosci. (2017) 43:16-24. doi: 10.1016/j.jocn.2017.04.028

31. Ljungman PLS, Andersson N, Stockfelt L, Andersson EM, Nilsson Sommar J, Eneroth K, et al. Long-term exposure to particulate air pollution, black carbon, and their source components in relation to ischemic heart disease and stroke. Environ Health Perspect. (2019) 127:107012. doi: 10.1289/EHP4757

32. Shin S, Burnett RT, Kwong JC, Hystad P, van Donkelaar A, Brook JR, et al. Ambient air pollution and the risk of atrial fibrillation and stroke: a population-based cohort study. Environ Health Perspect. (2019) 127:87009. doi: 10.1289/EHP4883

33. organization Wh. Depression: Let's talk. (2017).

34. Zeng Y, Lin R, Liu L, Liu Y, Li Y. Ambient air pollution exposure and risk of depression: a systematic review and meta-analysis of observational studies. Psychiatry Res. (2019) 276:69-78. doi: 10.1016/j.psychres.2019.04.019

35. Szyszkowicz M, Kousha T, Kingsbury M, Colman I. Air pollution and emergency department visits for depression: a multicity case-crossover study. Environ Health Insights. (2016) 10:155-61. doi: 10.4137/EHI.S40493

36. Cho J, Choi YJ, Suh M, Sohn J, Kim H, Cho SK, et al. Air pollution as a risk factor for depressive episode in patients with cardiovascular disease, diabetes mellitus, or asthma. J Affect Disord. (2014) 157:4551. doi: 10.1016/j.jad.2014.01.002

37. Szyszkowicz M, Tremblay N. Case-crossover design: air pollution and health outcomes. Int J Occup Med Environ Health. (2011) 24:24955. doi: 10.2478/s13382-011-0034-y

38. Szyszkowicz M, Rowe BH, Colman I. Air pollution and daily emergency department visits for depression. Int J Occup Med Environ Health. (2009) 22:355-62. doi: 10.2478/v10001-009-0031-6

39. Nuyts V, Nawrot TS, Scheers H, Nemery B, Casas L. Air pollution and selfperceived stress and mood: a one-year panel study of healthy elderly persons. Environ Res. (2019) 177:108644. doi: 10.1016/j.envres.2019.108644

40. Thomson EM, Filiatreault A, Guenette J. Stress hormones as potential mediators of air pollutant effects on the brain: rapid induction of glucocorticoid-responsive genes. Environ Res. (2019) 178:108717. doi: 10.1016/j.envres.2019.108717 
41. Reitmayer CM, Ryalls JMW, Farthing E, Jackson CW, Girling RD, Newman TA. Acute exposure to diesel exhaust induces central nervous system stress and altered learning and memory in honey bees. Sci Rep. (2019) 9:5793. doi: 10.1038/s41598-019-41876-w

42. Hajat A, Hazlehurst MF, Golden SH, Merkin SS, Seeman T, Szpiro AA, et al. The cross-sectional and longitudinal association between air pollution and salivary cortisol: Evidence from the Multi-Ethnic Study of Atherosclerosis. Environ Int. (2019) 131:105062. doi: 10.1016/j.envint.2019.105062

43. Khamirchi R, Moslem A, Agah J, Pozo OJ, Miri M, Dadvand P. Maternal exposure to air pollution during pregnancy and cortisol level in cord blood. Sci Total Environ. (2020) 713:136622. doi: 10.1016/j.scitotenv.2020.136622

44. Marketon JI, Sternberg EM. The glucocorticoid receptor: a revisited target for toxins. Toxins (Basel). (2010) 2:1357-80. doi: 10.3390/toxins2061357

45. Milo R, Kahana E. Multiple sclerosis: geoepidemiology, genetics and the environment. Autoimmun Rev. (2010) 9:A38794. doi: 10.1016/j.autrev.2009.11.010

46. Hedstrom AK, Olsson T, Alfredsson L. Smoking is a major preventable risk factor for multiple sclerosis. Mult Scler. (2016) 22:1021-6. doi: 10.1177/1352458515609794

47. Selmi C, Lu Q, Humble MC. Heritability versus the role of the environment in autoimmunity. J Autoimmun. (2012) 39:249-52. doi: 10.1016/j.jaut.2012.07.011

48. Zhao CN, Xu Z, Wu GC, Mao YM, Liu LN, Qian W, et al. Emerging role of air pollution in autoimmune diseases. Autoimmun Rev. (2019) 18:60714. doi: 10.1016/j.autrev.2018.12.010

49. Phillips G, Guo S, Bender R, Havrdova E, Proskorovsky I, Vollmer T. Assessing the impact of multiple sclerosis disease activity and daclizumab HYP treatment on patient-reported outcomes: Results from the SELECT trial. Mult Scler Relat Disord. (2016) 6:66-72. doi: 10.1016/j.msard.2016.02.001

50. Esmaeil Mousavi S, Heydarpour P, Reis J, Amiri M, Sahraian MA. Multiple sclerosis and air pollution exposure: mechanisms toward brain autoimmunity. Med Hypotheses. (2017) 100:2330. doi: 10.1016/j.mehy.2017.01.003

51. Wang Z, Xie J, Wu C, Xiao G. Correlation between smoking and passive smoking with multiple sclerosis and the underlying molecular mechanisms. Med Sci Monit. (2019) 25:893-902. doi: 10.12659/MSM.912863

52. Turk Boru U, Boluk C, Tasdemir M, Gezer T, Serim VA. Air pollution, a possible risk factor for multiple sclerosis. Acta Neurol Scand. (2020) 141:431-7. doi: 10.1111/ane.13223

53. Corona-Vazquez T, Flores Rivera JJ, RodriguezViolante M, CervantesArriaga A. Air pollution, multiple sclerosis and its relevance to Mexico city. Arch Med Res. (2019) 50:111-2. doi: 10.1016/j.arcmed.2019.07.003

54. Tateo F, Grassivaro F, Ermani M, Puthenparampil M, Gallo P. PM2.5 levels strongly associate with multiple sclerosis prevalence in the Province of Padua, Veneto Region, North-East Italy. Mult Scler. (2019) 25:171927. doi: $10.1177 / 1352458518803273$

55. Palacios N, Munger KL, Fitzgerald KC, Hart JE, Chitnis T, Ascherio A, et al. Exposure to particulate matter air pollution and risk of multiple sclerosis in two large cohorts of US nurses. Environ Int. (2017) 109:6472. doi: 10.1016/j.envint.2017.07.013

56. Costa ESJA, Steffen RE. Urban environment and psychiatric disorders: a review of the neuroscience and biology. Metabolism. (2019) 100S:153940. doi: 10.1016/j.metabol.2019.07.004

57. Engemann K, Svenning JC, Arge L, Brandt J, Geels C, Mortensen PB, et al. Natural surroundings in childhood are associated with lower schizophrenia rates. Schizophr Res. (2019) 216:488-495. doi: 10.1016/j.schres.2019.10.012

58. Peen J, Schoevers RA, Beekman AT, Dekker J. The current status of urbanrural differences in psychiatric disorders. Acta Psychiatr Scand. (2010) 121:84-93. doi: 10.1111/j.1600-0447.2009.01438.x

59. Liang Z, Xu C, Cao Y, Kan HD, Chen RJ, Yao CY, et al. The association between short-term ambient air pollution and daily outpatient visits for schizophrenia: a hospital-based study. Environ Pollut. (2019) 244:1028. doi: 10.1016/j.envpol.2018.09.142

60. Newbury JB, Arseneault L, Beevers S, Kitwiroon N, Roberts S, Pariante CM, et al. Association of air pollution exposure with psychotic experiences during adolescence. JAMA Psychiatry. (2019) 76:614-23. doi: 10.1001/jamapsychiatry.2019.0056
61. Qiu H, Zhu X, Wang L, Pan J, Pu X, Zeng X, et al. Attributable risk of hospital admissions for overall and specific mental disorders due to particulate matter pollution: a time-series study in Chengdu, China. Environ Res. (2019) 170:230-7. doi: 10.1016/j.envres.2018.12.019

62. Bai L, Zhang X, Zhang Y, Cheng Q, Duan J, Gao J, et al. Ambient concentrations of $\mathrm{NO}_{2}$ and hospital admissions for schizophrenia. Occup Environ Med. (2019) 76:125-31. doi: 10.1136/oemed-2018-105162

63. Duan J, Cheng Q, Luo X, Bai L, Zhang H, Wang S, et al. Is the serious ambient air pollution associated with increased admissions for schizophrenia? Sci Total Environ. (2018) 644:14-9. doi: 10.1016/j.scitotenv.2018. 06.218

64. Eguchi R, Onozuka D, Ikeda K, Kuroda K, Ieiri I, Hagihara A. The relationship between fine particulate matter (PM2.5) and schizophrenia severity. Int Arch Occup Environ Health. (2018) 91:613-22. doi: 10.1007/s00420-018-1311-x

65. Suades R, Padro T, Badimon L. The role of blood-borne microparticles in inflammation and hemostasis. Semin Thromb Hemost. (2015) 41:590606. doi: $10.1055 / \mathrm{s}-0035-1556591$

66. Thygesen M, Holst GJ, Hansen B, Geels C, Kalkbrenner A, Schendel D, et al. Exposure to air pollution in early childhood and the association with Attention-Deficit Hyperactivity Disorder. Environ Res. (2019) 183:108930. doi: 10.1016/j.envres.2019.108930

67. Mortamais M, Pujol J, Martinez-Vilavella G, Fenoll R, Reynes C, Sabatier $\mathrm{R}$, et al. Effects of prenatal exposure to particulate matter air pollution on corpus callosum and behavioral problems in children. Environ Res. (2019) 178:108734. doi: 10.1016/j.envres.2019.108734

68. Grandjean P, Landrigan PJ. Neurobehavioural effects of developmental toxicity. Lancet Neurol. (2014) 13:3308. doi: 10.1016/S1474-4422(13)70278-3

69. Lee SJ, Steiner RJ, Yu Y, Short SJ, Neale MC, Styner MA, et al. Common and heritable components of white matter microstructure predict cognitive function at 1 and 2 y. Proc Natl Acad Sci U S A. (2017) 114:14853. doi: 10.1073 /pnas. 1604658114

70. Ha S, Yeung E, Bell E, Insaf T, Ghassabian A, Bell G, et al. Prenatal and early life exposures to ambient air pollution and development. Environ Res. (2019) 174:170-5. doi: 10.1016/j.envres.2019.03.064

71. Kulas JA, Hettwer JV, Sohrabi M, Melvin JE, Manocha GD, Puig KL, et al. In utero exposure to fine particulate matter results in an altered neuroimmune phenotype in adult mice. Environ Pollut. (2018) 241:27988. doi: 10.1016/j.envpol.2018.05.047

72. Solaimani P, Saffari A, Sioutas C, Bondy SC, Campbell A. Exposure to ambient ultrafine particulate matter alters the expression of genes in primary human neurons. Neurotoxicology. (2017) 58:50-7. doi: 10.1016/j.neuro.2016.11.001

73. Wei H, Liang F, Meng G, Nie Z, Zhou R, Cheng W, et al. Redox/methylation mediated abnormal DNA methylation as regulators of ambient fine particulate matter-induced neurodevelopment related impairment in human neuronal cells. Sci Rep. (2016) 6:33402. doi: 10.1038/srep33402

74. Loop MS, Kent ST, Al-Hamdan MZ, Crosson WL, Estes SM, Estes MG, et al., et al. Fine particulate matter and incident cognitive impairment in the reasons for geographic and racial differences in stroke (REGARDS) cohort. PLoS One. (2013) 8:e75001. doi: 10.1371/journal.pone.0075001

75. Tonne C, Elbaz A, Beevers S, Singh-Manoux A. Traffic-related air pollution in relation to cognitive function in older adults. Epidemiology. (2014) 25:67481. doi: 10.1097/EDE.0000000000000144

76. Cleary EG, Cifuentes M, Grinstein G, Brugge D, Shea TB. Association of lowlevel ozone with cognitive decline in older adults. J Alzheimers Dis. (2018) 61:67-78. doi: 10.3233/JAD-170658

77. Chang KH, Chang MY, Muo CH, Wu TN, Chen CY, Kao CH. Increased risk of dementia in patients exposed to nitrogen dioxide and carbon monoxide: a population-based retrospective cohort study. PLoS One. (2014) 9:e103078. doi: 10.1371/journal.pone. 0103078

78. Lee KK, Miller MR, Shah ASV. Air pollution and stroke. J Stroke. (2018) 20:2-11. doi: 10.5853/jos.2017.02894

79. Zhang P, Dong G, Sun B, Zhang L, Chen X, Ma N, et al. Long-term exposure to ambient air pollution and mortality due to cardiovascular disease and cerebrovascular disease in Shenyang, China. PLoS One. (2011) 6:e20827. doi: 10.1371/journal.pone.0020827 
80. Stafoggia M, Cesaroni G, Peters A, Andersen ZJ, Badaloni C, Beelen R, et al. Long-term exposure to ambient air pollution and incidence of cerebrovascular events: results from 11 European cohorts within the ESCAPE project. Environ Health Perspect. (2014) 122:919-25. doi: 10.1289/ehp.1307301

81. Alimohammadi H, Fakhri S, Derakhshanfar H, Hosseini-Zijoud SM, Safari S, Hatamabadi HR. The effects of air pollution on ischemic stroke admission rate. Chonnam Med J. (2016) 52:53-8. doi: 10.4068/cmj.2016.52.1.53

82. Chiu HF, Chang CC, Yang CY. Relationship between hemorrhagic stroke hospitalization and exposure to fine particulate air pollution in Taipei, Taiwan. J Toxicol Environ Health A. (2014) 77:1154-63. doi: 10.1080/15287394.2014.926801

83. Xiang H, Mertz KJ, Arena VC, Brink LL, Xu X, Bi Y, et al. Estimation of shortterm effects of air pollution on stroke hospital admissions in Wuhan, China. PLoS One. (2013) 8:e61168. doi: 10.1371/journal.pone.0061168

84. Chen SY, Lin YL, Chang WT, Lee CT, Chan CC. Increasing emergency room visits for stroke by elevated levels of fine particulate constituents. Sci Total Environ. (2014) 473-474:446-50. doi: 10.1016/j.scitotenv.2013.12.035

85. Xu X, Sun Y, Ha S, Talbott EO, Lissaker CT. Association between ozone exposure and onset of stroke in Allegheny County, Pennsylvania, USA, 1994-2000. Neuroepidemiology. (2013) 41:2-6. doi: 10.1159/000345138

86. Wang F, Liu H, Li H, Liu J, Guo X, Yuan J, et al. Ambient concentrations of particulate matter and hospitalization for depression in 26 Chinese cities: A case-crossover study. Environ Int. (2018) 114:11522. doi: 10.1016/j.envint.2018.02.012

87. Kim KN, Lim YH, Bae HJ, Kim M, Jung K, Hong YC. Long-term fine particulate matter exposure and major depressive disorder in a community-based urban cohort. Environ Health Perspect. (2016) 124:154753. doi: 10.1289/EHP192

88. Costa LG, Chang YC, Cole TB. Developmental neurotoxicity of trafficrelated air pollution: focus on autism. Curr Environ Health Rep. (2017) 4:156-65. doi: 10.1007/s40572-017-0135-2

89. Genc S, Zadeoglulari Z, Fuss SH, Genc K. The adverse effects of air pollution on the nervous system. J Toxicol. (2012) 2012:782462. doi: 10.1155/2012/782462

90. Aalapati S, Ganapathy S, Manapuram S, Anumolu G, Prakya BM. Toxicity and bio-accumulation of inhaled cerium oxide nanoparticles in CD1 mice. Nanotoxicology. (2014) 8:786-98. doi: 10.3109/17435390.2013.829877

91. Steenhof M, Gosens I, Strak M, Godri KJ, Hoek G, Cassee FR, et al. In vitro toxicity of particulate matter (PM) collected at different sites in the Netherlands is associated with PM composition, size fraction and oxidative potential-the RAPTES project. Part Fibre Toxicol. (2011) 8:26. doi: 10.1186/1743-8977-8-26

92. Yonutas HM, Sullivan PG. Targeting PPAR isoforms following CNS injury. Curr Drug Targets. (2013) 14:733-42. doi: 10.2174/1389450111314070003

93. Chen L, Yokel RA, Hennig B, Toborek M. Manufactured aluminum oxide nanoparticles decrease expression of tight junction proteins in brain vasculature. J Neuroimmune Pharmacol. (2008) 3:286-95. doi: 10.1007/s11481-008-9131-5

94. Calderon-Garciduenas L, Solt AC, Henriquez-Roldan C, Torres-Jardon R, Nuse B, Herritt L, et al. Long-term air pollution exposure is associated with neuroinflammation, an altered innate immune response, disruption of the blood-brain barrier, ultrafine particulate deposition, and accumulation of amyloid beta-42 and alpha-synuclein in children and young adults. Toxicol Pathol. (2008) 36:289-310. doi: 10.1177/0192623307313011

95. Hartz AM, Bauer B, Block ML, Hong JS, Miller DS. Diesel exhaust particles induce oxidative stress, proinflammatory signaling, and P-glycoprotein up-regulation at the blood-brain barrier. FASEB J. (2008) 22:272333. doi: 10.1096/fj.08-106997

96. Luchi M, Munford RS. Binding, internalization, and deacylation of bacterial lipopolysaccharide by human neutrophils. J Immunol. (1993) 151:959-69.
97. Topinka J, Binkova B, Mrackova G, Stavkova Z, Benes I, Dejmek J, et al. DNA adducts in human placenta as related to air pollution and to GSTM1 genotype. Mutat Res. (1997) 390:59-68. doi: 10.1016/S0165-1218(96)00166-8

98. Ahmed A, Ghosh MK, Choi MC, Choi CH, Kim S. Which hydrogen atom of toluene protonates PAH molecules in (+)-mode APPI MS analysis? J Am Soc Mass Spectrom. (2013) 24:316-9. doi: 10.1007/s13361-012-0520-x

99. Saenen ND, Plusquin M, Bijnens E, Janssen BG, Gyselaers W, Cox B, et al. In utero fine particle air pollution and placental expression of genes in the brain-derived neurotrophic factor signaling pathway: an ENVIRONAGE birth cohort study. Environ Health Perspect. (2015) 123:83440. doi: 10.1289/ehp.1408549

100. Vrijens K, Winckelmans E, Tsamou M, Baeyens W, De Boever P, Jennen $D$, et al. Sex-specific associations between particulate matter exposure and gene expression in independent discovery and validation cohorts of middle-aged men and women. Environ Health Perspect. (2017) 125:6609. doi: 10.1289/EHP370

101. Kingsley SL, Eliot MN, Whitsel EA, Huang YT, Kelsey KT, Marsit $\mathrm{CJ}$, et al. Maternal residential proximity to major roadways, birth weight, and placental DNA methylation. Environ Int. (2016) 92-93:439. doi: 10.1016/j.envint.2016.03.020

102. Obolenskaya MY, Teplyuk NM, Divi RL, Poirier MC, Filimonova NB, Zadrozna $\mathrm{M}$, et al. Human placental glutathione S-transferase activity and polycyclic aromatic hydrocarbon DNA adducts as biomarkers for environmental oxidative stress in placentas from pregnant women living in radioactivity- and chemically-polluted regions. Toxicol Lett. (2010) 196:806. doi: 10.1016/j.toxlet.2010.03.1115

103. Kedryna T, Guminska M, Lucyna Z. Pyruvate kinase activity in the placentas of women living in polluted and unpolluted environments. Med Sci Monit. (2004) 10:CR672-8.

104. Luyten LJ, Saenen ND, Janssen BG, Vrijens K, Plusquin M, Roels HA, et al. Air pollution and the fetal origin of disease: a systematic review of the molecular signatures of air pollution exposure in human placenta. Environ Res. (2018) 166:310-23. doi: 10.1016/j.envres.2018.03.025

105. Tong H. Dietary and pharmacological intervention to mitigate the cardiopulmonary effects of air pollution toxicity. Biochim Biophys Acta. (2016) 1860:2891-8. doi: 10.1016/j.bbagen.2016.05.014

106. Zhong J, Trevisi L, Urch B, Lin X, Speck M, Coull BA, et al. B-vitamin supplementation mitigates effects of fine particles on cardiac autonomic dysfunction and inflammation: a pilot human intervention trial. Sci Rep. (2017) 7:45322. doi: 10.1038/srep45322

107. Zhong J, Karlsson O, Wang G, Li J, Guo Y, Lin X, et al. B vitamins attenuate the epigenetic effects of ambient fine particles in a pilot human intervention trial. Proc Natl Acad Sci U S A. (2017) 114:35038. doi: 10.1073/pnas.1618545114

108. Sarigiannis DA, Karakitsios SP. Addressing complexity of health impact assessment in industrially contaminated sites via the exposome paradigm. Epidemiol Prev. (2018) 42:37-48. doi: 10.19191/EP18.5-6.S1.P037.086

109. Vineis P, Robinson O, Chadeau-Hyam M, Dehghan A, Mudway I, Dagnino S. What is new in the exposome? Environ Int. (2020) 143:105887. doi: 10.1016/j.envint.2020.105887

Conflict of Interest: The authors declare that the research was conducted in the absence of any commercial or financial relationships that could be construed as a potential conflict of interest.

Copyright (C) $2020 \mathrm{Kim}$, Kim, Kim and Park. This is an open-access article distributed under the terms of the Creative Commons Attribution License (CC BY). The use, distribution or reproduction in other forums is permitted, provided the original author(s) and the copyright owner(s) are credited and that the original publication in this journal is cited, in accordance with accepted academic practice. No use, distribution or reproduction is permitted which does not comply with these terms. 